\title{
Study on Suitable Heating Pattern of Rural Residences in Shaanxi Province, China
}

\author{
LI Yanjun \\ School of Civil Engineering and Architecture, Xi'an University of Technology, Xi'an 710048, China. \\ 936069673@qq.com
}

\begin{abstract}
Keywords: Heating pattern, Rural residences, Ecological adaptation, Building energy efficiency Abstract. The Shaanxi province is long and narrow from north to south, covering three climate zones. There are enormous quantity and various kind rural residences. With development of era, there was a lack of professional guidance in local new village construction, and it led to some problems in rural areas, including serious resource waste, increase energy consumption, ecological destruction, and so on. The purpose of this paper was to explore suitable heating pattern of rural residences. The heating design temperature of rural residences was determined as $15^{\circ} \mathrm{C}$. Heating principles of rural residences were summarized and suitable heating technologies were analyzed. Finally, suitable heating pattern of rural residences were recommended. This research will provide reference for clean heating of rural residences. It makes a contribution to implement low carbon rural construction in China.
\end{abstract}

\section{Introduction}

In northern China, the winter here is very cold and it has a long duration. Under harsh climatic conditions, heating and thermal comfort of local buildings is an important issue, especially for local rural residences. Because rural residences were built up by villagers and they had various shortages, like poor thermal performance of building envelope, poor sealing performance, unreasonable layout of space, and so on. Meanwhile, traditional heating methods also had deficient like low heating efficiency. All these had drawn scholars' attention. Some scholars had focused on traditional Chinese heating facilities ${ }^{[1]-[6]}$.Some other scholars had focused on heating applications of solar energy ${ }^{[7]-[12]}$.

There are some specific climatic features in the middle and lower reaches of the Yangtze River in China. It is hot and rainy in summer, meanwhile it is cold and damp in winter. Even though indoor thermal environment was cold and humid in winter, but buildings in local were not heated in past era. With economic development and improvement of living standards, now local buildings' heating is already a common requirement for human. However, if heating mode in northern China were applied in local buildings, total energy consumption in China would be overwhelmed. So some scholars had focused on buildings' heating methods for the middle and lower reaches of the Yangtze River ${ }^{[13]-[18]}$.

In recent years, haze pollution had frequently occurred in China. Some scholars thought that haze pollution had obvious seasonal characteristics in China, and haze pollution were most severe in winter, meanwhile they affected a wide range, among of them, southern Hebei, northern Henan, southern Shanxi and Shaanxi's Guanzhong region were heavily polluted zones ${ }^{[19]}$.Some scholars thought that sources of haze pollution were mainly caused by man-made factors, including the consumption of traditional fossil fuels such as coal and petroleum, the emission of automobile exhaust, the emission of various industrial and domestic exhaust gases, and so on ${ }^{[20]}$.For these reasons, buildings' clean heating was proposed in China. Some scholars had focused on buildings' clean heating, and they had already got some remarkable research result ${ }^{[21]-[24]}$.

With social development and urbanization process, building energy efficiency was entering into a new stage in China. Some scientific concept was proposed. Prof. Long's research conclusion included the following: (1) Building energy efficiency was not an accumulation of single technology, but the comprehensive utilization of various technologies reasonably, and appropriate technology was the best one. (2) There should be fully inclusive in selection and evaluation of technology ${ }^{[25]}$.So integrated 
application of some basic building technologies was proposed and popularized. Some scholars had focused on integrated heating technology ${ }^{[26]-[28]}$.

Although domestic research in heating of buildings had been very intensive so far, but heating of rural residences in Shaanxi province still needed to be studied further. The terrain of Shaanxi province is long and narrow from north to south, covering three climate zones, including middle temperate zone, warm temperate zone and northern subtropical. Meanwhile, according to thermal design code for civil building, Shaanxi province is covering three thermal design areas, including severe cold zone, cold zone, hot summer and cold winter zone. In general, climate condition across Shaanxi province is very different. On the other hand, Shaanxi's Guanzhong region was heavily haze polluted zone, and clean heating was very important for local buildings. Because of these, so suitable heating pattern of rural residences in Shaanxi province was studied in this paper.

\section{Overview of Shaanxi Province}

Shaanxi province is located in east longitude $105^{\circ} 29^{\prime}-111^{\circ} 15^{\prime}$, north latitude $31^{\circ} 42^{\prime}-39^{\circ} 35^{\prime}$, in northwestern of China, and its capital city is Xi'an. Shaanxi province covers 205,800 [square kilometers], and there is about 880 [km] from north to south while there is $160 \sim 490$ [km] from east to west. Figure 1 shows place of Shaanxi province.

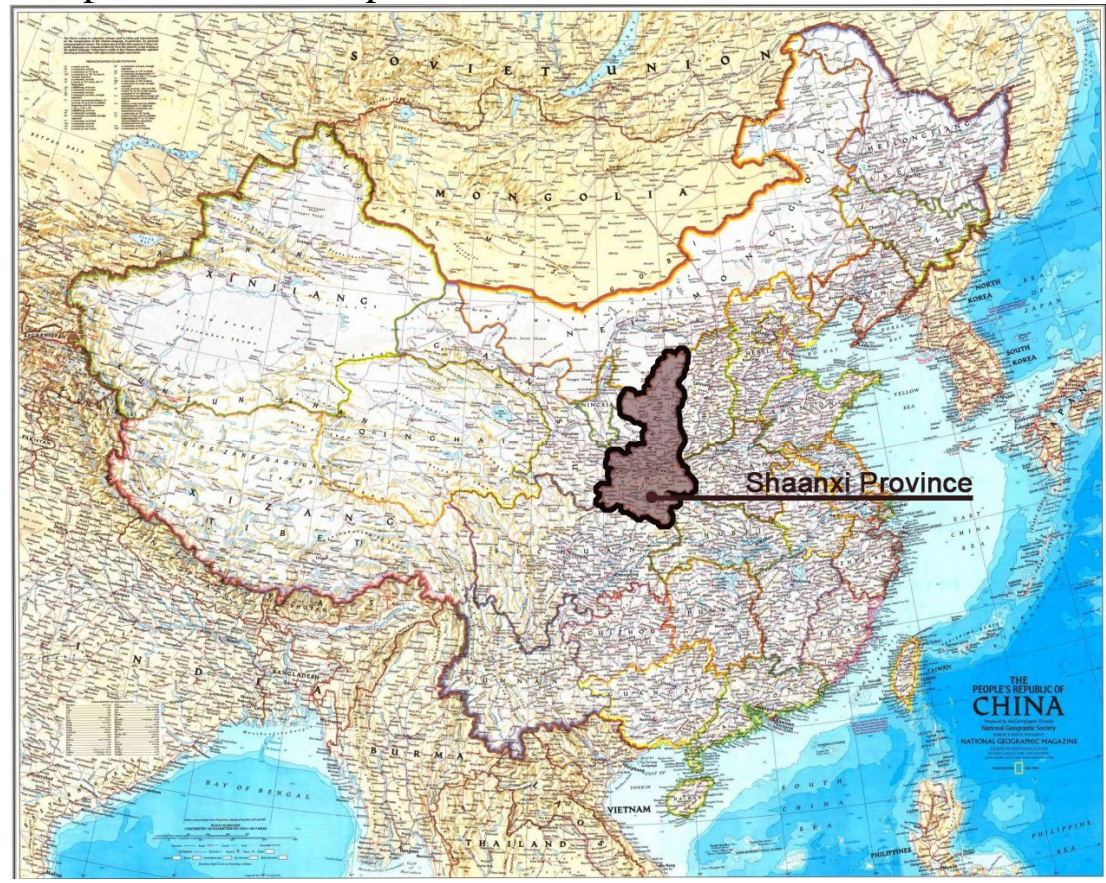

Fig.1. Shaanxi province of China

Table 1. Climate profiles of Shaanxi province ${ }^{[29]-[30]}$

\begin{tabular}{llccc}
\hline & Region & Northern region & Guanzhong region & Southern region \\
\hline Item & [annual] & $7 \sim 11$ & $11 \sim 13$ & $14 \sim 15$ \\
\hline Average temperature & {$\left[{ }^{\circ} \mathrm{C}\right]$} & $-10 \sim-4$ & $-3 \sim 1$ & $0 \sim 3$ \\
Temperature in January & {$\left[{ }^{\circ} \mathrm{C}\right]$} & $21 \sim 25$ & $23 \sim 27$ & $24 \sim 27.5$ \\
Temperature in July $\quad\left[{ }^{\circ} \mathrm{C}\right]$ & 463.4 & 670.9 & 925.3 \\
Rainfall $\quad[\mathrm{mm}]$ & $1000 \sim 1400$ & $2500 \sim 2900$ & $1900 \sim 2400$ & $800 \sim 900$ \\
Evaporation $\quad[\mathrm{mm}]$ & $150 \sim 195$ & $200 \sim 220$ & $1400 \sim 1900$ \\
Sunshine hours $\quad[\mathrm{h}]$ & $\quad[\mathrm{d}]$ & $240 \sim 269$
\end{tabular}

It's long and narrow from north to south. Because there are differences between geography, history, culture, climate, language and ethnic, so Shaanxi province was divided into three parts, including Northern region, Guanzhong region and Southern region. Shaanxi province has a typical continental 
monsoon climate. It has a cold and dry winter. In spring, there are drastic temperature changes and little precipitation. There is more sandstorm weather in Northern region, and there are hot weather and more thunderstorms in summer. There is more rainy weather in Southern region than Northern region. Table 1 shows climate profiles of three regions of Shaanxi province.

\section{Overview of Rural Residences in Shaanxi Province}

According to statistics result ${ }^{[31]}$, at the end of 2016, the average floor area per person of rural residences in Shaanxi province had reached 44.7 square meters, and there were 17.03 million people who lived in rural area.It was very easy to calculate that the total area of rural residences in Shaanxi province was about 761.2 million square meters at the end of 2016.These rural residences were classified according to heating facilities condition, and $0.1 \%$ of them were equipped with central heating, $60.9 \%$ of them were heated by the villagers in various ways, $39.0 \%$ of them were not heated ${ }^{[31]}$.

According to statistics result ${ }^{[32]}$, at the end of 2015,773,500 units energy-saving heating furnaces, 2.16 million units energy-saving cookstoves, 687,800 units energy-saving Chinese kangs were used in rural residences in Shaanxi province.Meanwhile,2.08 million square meters solar water heaters, 247392 units solar cookers, 2000 square meters sun house were also used.

Residential energy consumption per capita over the years were displayed in China Energy Statistical Yearbook ${ }^{[33]}$.Nearly 16 years data was selected and analyzed. Fig. 2 showed urban and rural per capita living energy comparative analysis. It can be seen that both urban and rural per capita living energy had been increasing in the past, but rural per capita living energy had grown even more violently. The comparative analysis of the data reflected that villagers' pursuit of comfortable and convenient living was consistent with that of urban residents.

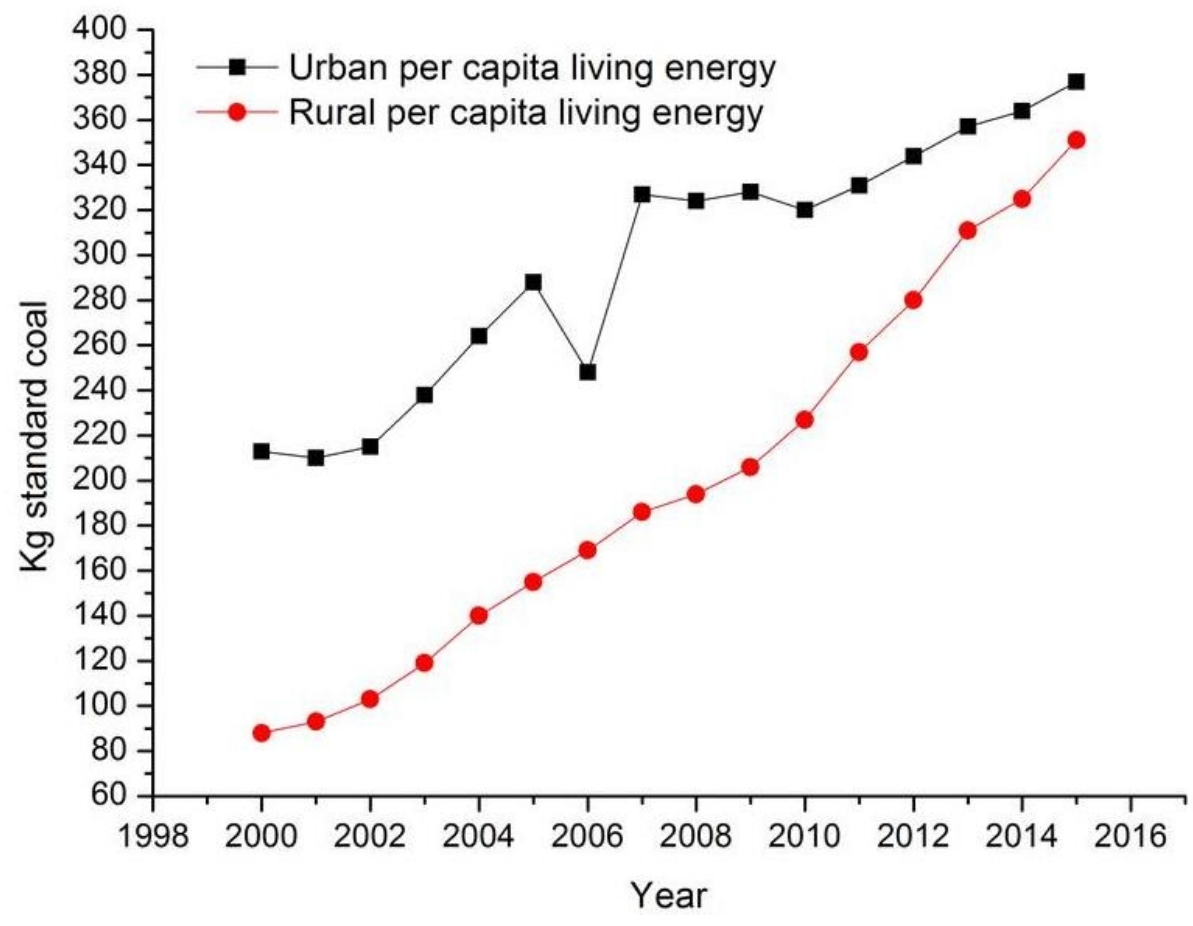

Fig.2. Urban and Rural per capita living energy comparative analysis

According to statistics result ${ }^{[33]}$, in 2015 , the energy consumption of rural residents in Shaanxi province was as follows: 2.3 million tons raw coal, 303100 tons petroleum products, 0.44 million cubic meters natural gas, 7.275 billion kilowatt hour electricity.

\section{Human Thermal Comfort and Heating Design Temperature}

With social development and improvement of living standards,people's requirements for indoor thermal environment were also getting higher.Thermal comfort is consciousness state that people are 
satisfied with specific thermal environment.Lots of scholars studied thermal comfort,and some scholars' research results were related to rural residences in Shaanxi province.

It was analyzed in a master thesis that in cold zone, acceptable temperature range for rural residents in winter was $9.0 \sim 15.8^{\circ} \mathrm{C}$, neutral temperature in winter was $11.6^{\circ} \mathrm{C}$, expectation temperature in winter of villagers was $12.7^{\circ} \mathrm{C}^{[34]}$. Some scholars pointed out that in Guanzhong region, neutral temperature in winter was $11.7^{\circ} \mathrm{C}$, expectation temperature in winter of villagers was $12.7^{\circ} \mathrm{C}$, and the minimum acceptable temperature in winter for $80 \%$ of villagers was $8.0^{\circ} \mathrm{C}^{[35]}$. Some scholars believed that in the hot summer and cold winter zone, indoor heating design temperature in winter should be $14.83^{\circ} \mathrm{C}$ ${ }^{[36]}$.Prof. DUANMU pointed out that heat neutral temperature in winter in rural China was between $11.6 \sim 18.5^{\circ} \mathrm{C}$, and its average was $15.4^{\circ} \mathrm{C}^{[37]}$.

Although villagers often adapted themselves to temperature changes in room and adjusted their comfort by adding clothes, but it may be uncomfortable to wear heavy clothes indoors. For living quality of residences, rural residents and urban residents had the same requirements. On the other hand, the heating problems of rural residences were studied in this paper. Therefore, the heating design temperature of rural residences in Shaanxi province was determined as $15^{\circ} \mathrm{C}$.

\section{Heating Principle of Rural Residences}

Full Consideration of Local Energy Conditions. Heating methods of rural residences should be adapted to local energy source conditions. All regions have their own different energy conditions. The annual sunshine hours in Northern region reached 2500 2900 hours, and the annual total solar radiation was 5000 5500 $\mathrm{MJ} / \mathrm{m}^{2}$, so Northern region was a very rich area of solar energy resources. Guanzhong region was a rich area of solar energy resources, and its annual total solar radiation was $4500 \sim 5100 \mathrm{MJ} / \mathrm{m}^{2}$.So it was obvious that in Northern region and Guanzhong region, solar energy has strong application value in buildings' heating. Southern region had north subtropical climate characteristics. Due to cloudiness, water vapor and other significant impact, solar energy resources in Southern region were common, but it was rich in firewood resources. It's well known that Northern region had very rich reserves of fossil fuels. So in heating of rural residences, the most suitable energy sources should be selected first of all, and all kinds of energy should be used fully and reasonably.

Full Consideration of Social Environment.Heating methods of rural residences should be adapted to social development. With development of the times, consumption concept of rural residents had changed. For performance and quality of rural residences, rural residents had higher requirements. The villagers' requirements for residences were as follows: complete functional partition, beautiful architectural appearance, safe building structure, privacy of personal living space. Building heating was attached to the building, so heating methods of rural residents must be adapted to building changes which caused by social development.

Full Consideration of Economic Conditions.Heating methods of rural residences should be adapted to residents' economic conditions.Building technology was indistinguishable, and building heating was a necessity for residents. So any technology which could meet the heating needs can be applied in rural residences.For low-income families, the traditional Chinese kang can create thermal comfort in a bedroom,passive sun room can create thermal comfort in winter sunny daylight. For high-income families, some of the latest building technologies may be used.Passive house could be built up and residential air source heat pump could be applied. So rural residents should choose their heating methods according to their own economic conditions.

Adaptation to the Villagers' Living Habits. Heating methods of rural residences should be adopted by local villagers, so they must adapt to the villagers' living habits. Some kind heating facilities have been accepted and used by villagers for a long time in certain areas. These heating facilities inevitably had more convergence points with the local climatic conditions, resource conditions, 
economic conditions and villagers' production methods, and so on. For these heating facilities, they should not be banned and replaced directly, but they should be optimized by improving heating efficiency and eliminating defects.

Be Friendly to Natural Environment.Nowadays buildings' clean heating was more and more recognized by the public. Buildings' clean heating had many benefits. It not only reduced carbon dioxide emissions, but also achieved sustainable development, meanwhile it reduced haze pollution in winter. How to realize clean heating for rural residences ?First of all ,renewable energy should be full used.There were abundant solar energy resources in Northern region and Guanzhong region of Shaanxi province, and there was huge biomass reserve in rural region, so all of these advantages should be used in order to improve thermal environment of rural residences in winter. The second, with the development of science and technology, there have been many new heating technologies and new products, including solar hot water collector, heat pump heating, electric heating film, heating cable, and so on. All of these can ensure buildings' clean heating.

\section{Analysis of Suitable Heating Technology}

Heating Control Technology Variation According to Building Space Division.Building thermal environment should be regulated and controlled in order to meet human needs. But people used different building spaces at different times, and these building space had different thermal comfort standards. So building thermal environment should be regulated and controlled by building space division. In this way, each technology played its own advantage. For example, a building was divided into southern part and northern part, and southern part can make full use of solar energy to satisfy human thermal comfort easily in winter sunny daylight. Meanwhile, northern part can be heated by use of other appropriate technology.In the meantime, different heating control technology are implemented between main space and auxiliary space.Heating control technology variation according to building space division had the most advantages, on the one hand, it satisfy human thermal comfort needs in different space immediately,on the other hand, it uses necessary heating energy consumption without any waste.

Heating Control Technology Variation According to Day and Night Alternation of Time. The house was just a building and it was be used by human. Building heating mainly served users of the building. Each building space was mainly used at different time, so building heating of each space should be adjusted with whether building space is used. The dining room was mainly used for three meals. The bedroom was mainly used by night until the next morning, and some Chinese had habits of having a nap after lunch, so the bedroom was also used for a period of time at noon. In winter, most villagers reunited in the living room during daytime and they watched TV in the living room at night until before going to sleep. These three kinds rooms were mainly building space which should be heated enough to suit needs of the user. It's evident that living room was mainly used during the daytime. So passive sun room technology should be used in the living room. Then the living room can be heated by solar energy at low cost. At night, living room can be heated by other heating facilities, or it can be heated by active sun room technology at higher cost. Solar energy has many advantages, such as clean, renewable, large reserves, easy to use, and so on. So in heating of rural residences, solar energy should be fully utilized.

Heating Control Technology Variation According to Energy Types and Reserves. Comprehensive utilization of various technologies reasonably would gain a great advantage in heating of rural residences. A variety of energy sources, such as electricity, coal, biomass, solar energy, natural gas, etc., can be used for building heating. Similarly, there was a variety of heating technology which matched with energy sources. Solar energy and biomass fuel, which both was clean, ecological and renewable energy sources, but they were unstable. Electric power had advantages of quick response and convenience adjustment in heating of building, but it was expensive. Burning coal in heating of building was not conducive to environment protection, but the coal was easily accessible and stable. Natural gas was clean energy source, but its energy reserve was small in China. So composite heating 
of diverse energy sources was the most suitable pattern for rural residences, which maximized the advantages of diverse energy sources and complemented the deficiencies each other.

\section{Suitable Heating Pattern of Rural Residences in Shaanxi Province}

Rural residents should consider various factors, and choose their own heating methods or a combination heating.

In Northern region of Shaanxi province, for low-income families, passive solar house can be mainly applied in southern part of building, and suspended energy saving kang can be mainly applied in northern part of building.Electric heater, electric blankets and coal-fired stove can be added or replaced. For high-income families, active sun room technology can be mainly applied in southern part of building, and boiler hot water system can be mainly applied in northern part of building.

In Guanzhong region of Shaanxi province, for low-income families, the recommended heating pattern was the same as in Northern region. For high-income families, active sunroom technology and air source heat pump system both can be mainly applied in whole building. Split air conditioner can be added or replaced.

In Southern region of Shaanxi province, for low-income families, suspended energy saving kang and firewood stove can be mainly applied in whole building. For high-income families, electric heater and split air conditioner can be mainly applied in whole building.

\section{Conclusions}

Through above analysis and discussion on heating problems of rural residences, conclusions were summarized as follow:

(1) The heating design temperature of rural residences in Shaanxi province was determined as $15^{\circ} \mathrm{C}$.

(2) There were several factors that must be considered when determining the heating method for rural residences, including local energy conditions, social environment, economic conditions, villagers' living habits, be friendly to natural environment, and so on.

(3) There were several factors that must be considered when determining the suitable heating technology for rural residences, including building space division, alternation of time, energy types and reserves.

(4) Suitable heating patterns for three regions and different income families were recommended.

\section{Acknowledgements}

This work was financially supported by Shaanxi Provincial Department of Housing and Urban-Rural Development( 2015-K74 ), Shaanxi Provincial Department of Education( 16JK1564 ), Xi'an University of Technology ( 118-211417). The author wishes to express his most sincere appreciation to these three units.

\section{References}

[1] ZHANG Baogang, YUAN Pengli, LIU Ming.Analysis of indoor thermal environment of the building heated by fire pit [J].Journal of Harbin Engineering University, 2015,Vol.36(11):1471-1475 .

[2] ZHANG Bao-gang, DU Guang-wen, LIU Ming. Experimental study of rural winter heating system based on smoldering cave hot-water coil heating [J].Architecture Technology, 2015,Vol.46(11):987-992 . 
[3] YU Jin, WANG Cheng, YANG Zhiwei. Experimental study on Energy Conservation Performance of Hot-Wall Kang with Heating Collector [J].Journal of Shenyang Jianzhu University(Natural Science), 2015,Vol.31(6):1091-1098 .

[4] DUANMU Lin, YUAN Pengli, XU Ce. Thermal performance and heating capacity of hot-wall Kang [J]. Journal of Thermal Science and Technology, 2016,Vol.15(1):59-66 .

[5] ZHAO Xi-ping, ZHANG Peng, ZHOU Tie-gang. Influence of Hot-wall on Rural Residential Thermal Environment in Severe Cold Areas [J]. Building Energy Efficiency, 2016,Vol.44:1-5 .

[6] Li Jinping, Li Hongbo, Zheng Jian. Contrast test of thermal properties of suspended kang and traditional landed kang[J].Transactions of the Chinese Society of Agricultural Engineering, 2017,Vol.33(14):210-216 .

[7] Feng Ya, Yang Xudong, Zhong Huizhi.Heating potential of passive solar building in Lhasa [J].Journal of Heating Ventilating \& Air Conditioning, 2013,Vol.43(6):31-34 .

[8] Li Hongyan, He Jianguo, Li Mingbin.Performance test and analysis of solar floor radiation heating in Yinchuan region [J].Journal of Heating Ventilating \& Air Conditioning, 2015,Vol.45(10):86-90 .

[9] Guo Huaiyun, Liu Yanfeng, Ma Chao. Analysis on the solar heating mode adaptation in northwest rural region [J].CHINA SCIENCE PAPER, 2015, Vol.10(1):31-34 .

[10] Wang Chun, Jiang Shuguang, Cheng Bo. Experimental study on heating of the system combined solar wall with basement in winter [J].Acta Energiae Solaris Sinica, 2016,Vol.37(3):678-683 .

[11] LIU Zhijian, YU Hancheng,MA Wensheng.Numerical Simulation of Thermal Performance of Passive Solar House in the Qinghai Alpine Pastoral Areas [J].Building Science, 2016,Vol.32(4):15-19 .

[12] Li Jinping,Wang Lei,Li Xiuzhen. Experimental study on active solar heating for new rural residence in northwest China [J].Renewable Energy Resources, 2016,Vol.34(11):1680-1685 .

[13] ZHANG Qianqing,SHI Hongliu.Energy analysis of the typical city heating mode in hot summer and cold winter zone [J].Sichuan Building Science, 2015,Vol.41(3):228-233 .

[14] SHI Hongliu,WANG Zhiwei,YAN Zengfeng.Indoor design temperature research for heating in hot summer and cold winter zone [J].Sichuan Building Science, 2015,Vol.41(4):123-131 .

[15] XU Min-chao,ZHANG Yan,HAN Zhi.The Ultra-thin Ceramic Tile Radiation Heating Design for Building in Hot Summer and Cold Winter Zone [J].Energy Conservation Technology, 2016,Vol.34(197):247-249 .

[16] Chen Jinhua, Zhang Jing, Fan Lingxiao . Analysis of thermal environment and heating status of residential buildings in Chongqing area in wintet [J].Journal of Heating Ventilating \& Air Conditioning, 2016,Vol.46(11):90-94 .

[17] LI Ning, LIU Wan-long.Application Test and Analysis of Radiant Floor Heating System with Air -source Heat Pump in Shanghai Area [J]. Building Energy \& Environment, 2017,Vol.36(8):68-73 . 
[18] KAN Suyu . Analysis of heating mode in hot summer and cold zone [J]. Heating \& Refrigeration , 2017.8:32-33 .

[19] ZHANG Sheng-ling,WANG Yu-han,LI Yue.Spatial distribution of haze pollution and its influencing factors [J].China Population,Resources and Environment, 2017,Vol.27(9):15-22 .

[20] GAO Guangkuo, WANG Qiongpu. Research Progress on the Formation Mechanism of Haze Pollution in China [J]. Ecological Economy, 2017,Vol.33(9):106-109 .

[21] ZHANG Qunli, LI Yinlong,LIU Baoshan.Suitability Analysis of the Heating Method of Low Temperature Air Source Heat Pump Applied in North China [J].Building Science, 2015,Vol.31(2):140-145 .

[22] Ning Meiling, Yuang Pengli,Zhao Xin. The Application of Hot Water Heating System Based on a New Type Biomass Stove[J]. Refrigeration and Air Conditioning, 2015,Vol.29(6):666-672 .

[23] Jiang Jianyun,Zhang Yongjie,Ye Jiandong.Effectiveness comparison and analysis of alternative solutions to coal-fired heating in rural Beijing[J].Journal of Heating Ventilating \& Air Conditioning, 2016,Vol.46(9):51-55 .

[24] CHEN Xiao-ning,YANG Zhi-yu,CHEN Jiang-ping.Research on Operating Characteristics of Floor Heating System with Residential Air Source Heat Pump.Architecture Technology, 2016,Vol.47(11):990-993 .

[25] Long Weiding. Thinking on building energy efficiency 2.0[J]. Heating Ventilating \& Air Conditioning, 2016,Vol.46(8):1-12 .

[26] Chen Mingdong,Shi Yuliang. Improvement of indoor thermal environment of rural residences with coupled heating of attached sunspace and energy saving hot-wall[J].Transactions of the CSAE, 2011,Vol.27(11):232-235 .

[27] ZHANG Bao-gang,LIU Ming,DU Guang-wen.Study on properties of low energy consumption eco-rural residence integrated optimized heating technology in northeast China[J]. Journal of Dalian University of Technology, 2015,Vol.55(2):127-133 .

[28] ZHAO Xin, WANG Zong-shan,YUAN Peng-li.Performance of Heating System which Combines with Radiator based on Biomass Cooking-stove and Thermal Storage Floor[J]. Building Energy \& Environment, 2017,Vol.36(2):6-10 .

[29] Anonymous ,Shaanxi climate. http://www.dreams-travel.com/shanxi-/Weather.htm.

[30] Shaanxi Provincal Department of Water Resources. Water conservancy basic situation of Shaanxi Province [R], 2001.

[31] Shaanxi Provincial Bureau of Statistics, Shaanxi Investigation Corps of National Statistics Bureau . Shaanxi Statistical Yearbook 2017[M].Beijing: China Statistics press,2017.

[32] Ministry of Agriculture of the People's Republic of China. China Agriculture Statistical Report 2015[M].Beijing: China Agricultural press,2016.

[33] Energy Statistics Division, National Bureau of Statistics. China Energy Statistical Yearbook 2016[M].Beijing: China Statistics press,2016. 
[34] Yang Qian. Study on the Indoor Thermal Comfort in the Cold Zone[D]. Xi'an: Xi' an University of Architecture and Technology, 2010.

[35] YANG Liu, YANG Qian, YAN Hai-yan.Field study on thermal comfort of a rural houses in winter in the Guanzhong region,Shaanxi Province[J].J. Xi' an Univ. of Arch. \& Tech.(Natural Science Edition), 2011,Vol.43(4):551-556 .

[36] SHI Hongliu, WANG Zhiwei, YAN Zengfeng.Indoor design temperature research for heating in hot summer and cold winter zone[J]. Sichuan Building Science, 2015,Vol.41(4):123-127 .

[37] DUANMU Lin, SUN Xingwei, LI Xiangli.Relationship between Human Thermal Comfort and Indoor Thermal Environment Parameters in Various Regions of China[J]. Building Science, 2017,Vol.33(6):115-122 . 